\title{
Exploring recent trends in youth justice reconvictions: a challenge to the complexity thesis
}

\section{Tim Bateman and Ali Wigzell}

\section{Youth Justice journal pre-publication proof October 2019}

\begin{abstract}
In recent years it has become accepted wisdom that children subject to youth justice intervention, in England and Wales, are more complex than previously, as a consequence of a substantial rise in diversion from the system that filters out children with lower levels of need and less entrenched offending. This 'complexity' thesis has been used to explain rises in rates of reoffending. This article demonstrates that the patterns shown in the reoffending data are not those that would be predicted by the complexity thesis. Indeed the data suggests that some groups of children may be less entrenched in offending than hitherto.
\end{abstract}

\section{Introduction}

Since 2010, reducing reoffending has been one of the formal measures of youth justice performance, and arguably, from a political perspective, the key indicator of the effectiveness of youth justice intervention. Yet the reoffending target has, to date, received little academic attention. As a consequence, trend data which appear to show that children's recidivism was falling consistently up to 2008 but has, in the intervening period, shown an opposite trajectory, have been subject to little critical scrutiny. This is in spite of their considerable potential to influence youth justice policy and practice. This article aims to go some way to filling that gap.

At the same time, rising reoffending rates for children have frequently been explained in terms of what we refer to as the 'complexity thesis': the suggestion that children who enter the youth justice system have higher levels of needs and are more entrenched in patterns of 
offending than hitherto. As a consequence, the risk of reoffending for this group is said to be higher than it was a decade ago. Analysis of the reoffending data does not, however, support such a suggestion in any straightforward manner. We argue that the thesis is accordingly inadequate as an explanation of recent trends. This is not to dispute that the youth justice population may be more complex on a variety of measures than hitherto. It is simply to maintain that such changes, if they have occurred, do not explain recent shifts in rates of reoffending as they are sometimes assumed to do.

We begin by critically reviewing the recent history, and value, of the use of reoffending rates, as a measure of effectiveness, before engaging in an exposition of recent reoffending data, their relationship to the complexity thesis, and a preliminary exploration of how they might be best understood.

\section{The focus on reoffending}

Trends for detected youth crime, as is well known, cannot be taken as unproblematic indicators of the extent of children's lawbreaking since they are equally manifestations of shifts in youth justice policy and practice (Bateman, 2015). For instance, diversionary strategies implemented by successive governments in England and Wales, in the recent period, have led to a rapid contraction of that system. The Youth Crime Action Plan (YCAP), published in 2008 (Home Office, 2008), committed the government to achieving a reduction in the number of children entering the youth justice system for the first time - so called first time entrants (FTEs) - and this target has been a prominent feature of youth justice policy for all subsequent governments. The measure has had a dramatic impact on the size of the youth justice cohort: between 2008 and 2018, the number of total proven offences committed by children has declined by $75 \%$, largely accounted for by a fall in FTEs (Youth Justice Board/ Ministry of Justice, 2019).

These developments contrast dramatically with those in the period immediately prior to the FTE target. Between 2003 and 2007, there was as sharp expansion in the number of children subject to formal youth justice disposals, a trend also explicable in terms of government policy. A target to increase the number of 'offences brought to justice' introduced in the earlier year (commonly referred to as the sanction detection target) led to an increase of $22 \%$ in the number of children entering the criminal justice system by 2007 . This was a 
consequence of net-widening, a process whereby children were criminalised for behaviour that would not previously have received a formal sanction (Bateman, 2017).

There have accordingly been sizeable fluctuations in the level of proven youth crime over the past 15 years, but these are thus best understood primarily as an artefact of changing political priorities rather than an indication of changes in children's offending behaviour. Such an understanding has significant implications for the focus of the current article since similar considerations apply to data on reoffending, which also rely on offending that is detected and receives a formal sanction.

For reasons outlined in due course, reoffending has for some years been regarded by the government as one of the primary measures of the effectiveness of the youth justice system. ${ }^{1}$ In that context, it is instructive to reflect on how interpretations of evidence relating to that indicator can be influenced by political expediency. It is, perhaps, not surprising that when data suggested that there had been a reduction in one year recidivism rates, following a youth justice disposal, of 7.3 percentage points between the first quarter of 2000 and the equivalent period in 2008 (Ministry of Justice, 2010), the government was quick to claim that this demonstrated that '[their] approach to youth crime was working' (Department for Children, Schools and Families, 2010: 1). In fact, the trend was more convincingly explained as a predictable outcome of net-widening, itself triggered by the drive to increase the number of formal sanctions imposed, so that children whose behaviour would not previously have been thought to warrant a formal youth justice response were increasingly criminalised. As a consequence, the profile of those within the system in 2008 had changed considerably since the baseline year of 2000 , with the former characterised by a substantially higher representation of girls, younger children and those processed for minor misdemeanours. The comparison, on the basis of which claims of effectiveness were made, was thus unreliable since the latter cohort was demonstrably less likely to offend. Empirical analysis, published at the time, confirmed that the reduction in recorded reoffending was largely accounted for by children who, but for the sanction detection target, would not have received a formal disposal (Bateman, 2010).

\footnotetext{
${ }^{1}$ While we use the term reoffending rate, we acknowledge that this refers only to detected reoffending since about half of offences are reported and around a quarter of these that are detected (Bateman, 2006).
} 
In line with other commentators, the government subsequently appears to have accepted the logic of this argument. Rates of reoffending following contact with the youth justice system have tended to climb since 2008 , but this rise is frequently explained in terms of the shifting profile of children captured by the data, rather than as indicative of a deterioration in the performance of the youth justice system. For instance, the incumbent Chair of the Youth Justice Board has referred to a 'smaller, more challenging cohort of children who offend' who are 'the most difficult to rehabilitate' (Taylor, 2016: 2-7). More generally, the government has attributed rising recidivism to a cohort with 'an increasing propensity to offend' (Ministry of Justice, 2017: 8).

In this sense, the dominant explanation of the escalation in rates of reoffending has relied on a discourse based on what we term the complexity thesis; the suggestion that the contraction in the youth justice population has been accompanied by what Alun Michael has referred to as 'a thickening of the soup... a residue of much more difficult cases from difficult backgrounds, much more embedded perhaps in a culture of offending' (cited in House of Commons Justice Committee, 2014: 94). The complexity thesis might thus defined as the view, largely accepted by the Youth Justice Board, that

'the young people who are left in the system now are the most challenging to work with. This was due to, among other reasons, more complex family backgrounds, more mental health issues, more group or gang offending and more serious youth violence' (Youth Justice Board, 2015: 15).

This shift is understood primarily to be a consequence of the diversion from the system of large numbers of children involved in low-level offending (Carlile, 2014; Taylor, 2016; Bateman, 2017). At the same time, the cohort of children who continue to attract formal sanctions are also widely said by youth justice professionals to have greater needs than previously (Her Majesty's Inspectorate of Probation, 2017; Wigzell, forthcoming; Carlile, 2014; Gray, 2013). A recent stocktake of youth offending teams, for instance, noted that services 'reported an increasing complexity of need in the young people dealt with' (Deloitte, 2015: 4).

In the abstract, Ministry of Justice data appear to be broadly consistent with such an explanatory account: the reoffending rate in the year ending March 2016 was 5.2 percentage points higher than in 2008; over the same period, the average number of re-offences per child 
also increased from 3.13 to 3.83 (Youth Justice Board / Ministry of Justice, 2018). On closer inspection, however, the picture is less straightforward than these headline figures suggest. In particular, reoffending by children subject to community sentences has fallen steadily since 2008. In the light of such evidence, this article accordingly questions whether recidivism data do in fact provide evidential support for the suggestions that the youth justice cohort has become more complex and 'criminogenic' in the manner that is widely assumed. (This is not to deny that there may be other such forms of evidence.)

The challenge to the complexity thesis developed here is, thus, a partial one. It relates to its deployment as an explanation of recent trends in recidivism rather than to the thesis itself. The paper does not explore whether claims that the current youth justice cohort has greater needs than previously have empirical support. The issue of whether 'increased complexity is a genuine phenomenon or a symptom of YOTs' assessment tools becoming more sophisticated' is not addressed in any detail (Deloitte, 2015: 4).

National data that would allow examination of this question are not collected in a consistent fashion and the available empirical evidence is accordingly limited. Nonetheless, a number of commentators, as noted above, have reported a wide consensus amongst youth justice professionals of this trend (Deloitte, 2015: Youth Justice Board, 2015; Wigzell, forthcoming). Moreover, there is some evidential support so far as children in the secure estate are concerned: surveys of children in young offender institutions and secure training centres suggest that the current custodial population displays higher levels of need than their contemporaries in previous periods (Green, 2019). Given the rise in diversionary practice over the past decade, there is, moreover, a clear logic for considering that the needs profile of children in the youth justice system is likely to have changed. The complexity thesis, as a description of shifts in the youth justice population, may be true, but this is an issue for further research and lies beyond the scope of the current paper.

For present purposes, the argument is thus narrowly construed. It contests discourses that purport to explain recidivism as a function of complexity; conversely, it also questions accounts that cite rises in reoffending as evidential support for the more complex nature of the youth justice population (see for instance, Bateman and Hazel, 2014). 
The argument developed is that, if the predominant explanation of the earlier reduction in reoffending demonstrated an unwarranted assumption that recidivism was a direct manifestation of the effectiveness of system intervention, more recent accounts of the subsequent rise in reoffending fail to acknowledge the different nuances shown in the data. The changing characteristics of the youth justice population prove to be just one strand in a broader fabric of contributory factors.

\section{Reoffending: a questionable measure of performance}

With the advent of what has become known as the 'new youth justice' (Goldson, 2000: ix), reoffending rates have increasingly been considered as the key litmus test of youth justice success (Bateman, 2010; for similar trends in probation, see Canton, 2012). Although comprising just one of the three youth 'performance indicators' introduced by the Coalition government in 2010, a glance at government pronouncements on youth justice confirms that reoffending continues to be the primary concern (see, for example, Gove, 2015). ${ }^{2}$ A growing preoccupation with recidivism was formalised by section 37 of the Crime and Disorder Act 1998, which established that the principal aim of the youth justice system was to 'prevent offending by children and young persons'. To eliminate potential confusion, the section was subsequently amended by the Criminal Justice and Immigration Act 2008 to confirm that the reference to offending included reoffending (Bateman, 2010). The roots of this fixation can no doubt be found in late modernity, characterised by the politicisation of crime, an enthusiasm for managerialism that emerged in the late 1970s (Canton, 2012; for a discussion of such changes see also Farrow et al, 2007; and Garland, 2002), and an increasingly risk averse stance to the provision of public services, manifested in the development of a youth justice assessment framework that purported to measure the risk of reoffending (Kemshall, 2008).

This focus on reducing children's delinquent behaviour is not in itself obviously irrational. Certainly, it is hard to imagine that anyone would promote an increase in offending. In this sense, one would naturally expect youth justice practitioners to be concerned with - among other things - supporting the children with whom they work to move, over the longer-term at least, towards a non-offending lifestyle. (For a

\footnotetext{
${ }^{2}$ The three performance indicators are reducing: first time entrants to the youth justice system; the use of custody; and reoffending (Youth Justice Board, 2017).
} 
discussion of the assumption that the point of the criminal justice system is to reduce crime see Canton, 2012). But such considerations do not imply endorsement of the current focus on proven reconviction. The existing measure has been widely criticised as a flawed indicator of effectiveness, a blunt gauge of progress towards 'desistance', as well as being overly narrow and deficit-focused (Criminal Justice Alliance, 2011; Bateman, 2010; 2016a).

We have already noted that the relationship between detected reconviction and effectiveness is, at best, indirect and that treating recidivism as a proxy for youth justice performance is problematic. It is also frequently conceded - including by the government itself - that the binary ('yes'/ 'no') rate of reoffending is an extremely blunt measure of the trajectory of an individual's criminal behaviour as it does not capture changes in the frequency or nature of their offending (Bateman, 2016b; Criminal Justice Alliance, 2011; Home Office, 2004; Ministry of Justice, 2008). A twelve month follow-up period is unhelpfully short-term and incompatible with longer-term developmental processes associated with the transition from childhood to maturity. These factors are significant because desistance is a protracted process, characterised by 'a pendulum of ambivalence' (Burnett, 2004: 169; see also McNeill, 2006) and drifting in and out offending (Matza, 1964). Thus, a 16-year-old boy who had committed several robberies over a short period, subsequently not offended for six months and then engaged in minor shoplifting, might reasonably be considered to be showing signs of growing out of crime (Rutherford, 1992; Bateman, 2014). Yet, under the binary measure, they would be recorded a 'failure'.

Reoffending rates are essentially deficit-focused, negative, measures insofar as they foreground the absence of an activity from an individual's life rather than taking account of achievements, They are rooted in what has become known as the 'risk factor prevention paradigm' which has, at least until recently, tended to dominate youth justice policy and practice on the basis of constructing the child as a repository for risks that need to be corrected (Case, 2018). There is little scope in this model for recognising the widespread and transitory nature of youthful offending behaviour which, in the large majority of cases, is left behind as children make the transition to adulthood (McVie, 2005). It fails to acknowledge the importance of agency in the journey towards a non-offending lifestyle that is enhanced by a future orientation and a focus on the child's strengths, desires and ambitions since it ties them to their past transgressions (Haines and Case, 2015). In this sense, a focus on reoffending is in tension with the Youth Justice Board's (2019) recent conversion to a vision based on 'child first' principles. It measures children's progress on the basis that they have not broken the law rather than in terms of any other, arguably more meaningful, achievements they have made and diverts policy makers' and 
practitioners' attention away from issues to do with wellbeing and longer term development towards an emphasis on short term metrics (National Association for Youth Justice, 2018). Finally, it presupposes that a single episode of law breaking, however minor, is indicative of a failure to engage in desistance, in spite of the overwhelming evidence that the latter is sometimes a lengthy process, that may be 'punctuated by occasional failures and relapses into crime, even after progress has been made' (Her Majesty's Inspectorate of Probation, 2016, 31).

Thus, returning to our imagined 16-year-old, there may have also been significant improvements in school attendance, mental well-being and engagement with the youth offending service, providing further indication of a movement away from crime. Yet the favoured measure of effectiveness does not take account of such progress. In contrast, at a local level, there is some evidence that youth justice practitioners conceptualise success primarily in terms of 'small steps', such as improved well-being and better supervisory relationships, with cessation in reoffending considered as a rather remote aim that will ensue over the longer term (Wigzell, forthcoming; see also Johns et al, 2017).

In this respect, it is noteworthy that this emphasis on reoffending is a relatively recent phenomenon. Prior to the 1998 reforms, work with children in trouble was largely undertaken by social workers as part of children's social care, in line with the duty to uphold the welfare of children in need, in accordance with the Children Act 1989 (Audit Commission, 1996). Historically, youth justice practitioners have tended to focus on promoting the longer-term healthy development of children with whom they work, rather than concentrating on whether they can avoid the imposition of a formal disposal over a twelve month period, on the assumption that the former would encourage the natural process of desistance in any event Haines and Drakeford, 1998; for a more recent endorsement of such an approach, see National Association for Youth Justice, 2018).

Canton (2012) has argued compellingly that the ethics and effectiveness of probation have been stymied by an explicit concern with reducing reoffending, enforcement and public protection and that work with adult offenders would be better served by a human rights-based, personal approach premised on the principle of obliquity (the idea that goals are often best achieved indirectly). This argument is equally relevant to youth justice.

\section{Methodology}


The argument developed in this paper relies heavily on national official statistics for children's one year reoffending between 2008 and 2016, published by the Ministry of Justice. This period was selected because the FTE target was introduced in the former year, triggering a rapid contraction in the youth justice population and an associated rise of a discourse that relies on the complexity thesis. Figures for 2016 were the latest available at the time of writing. We also draw on trend data for the number of children cautioned or convicted, published by the Youth Justice Board / Ministry of Justice, and data on the custodial population, over the same period. To allow consistent comparison a cutoff date of 2016 has been adopted for this latter data as well, even though more recent figures are available. ${ }^{3}$ The analysis involves detailed interrogation of these various datasets, with elements of integration and disaggregation of, and comparison between, figures from each of the sources, in order to present an original and more nuanced account of the statistical information than that suggested by the headline data that may be derived from each.

The primary focus of the analysis is to explore how recidivism trends for different disposal types might be best understood and the extent to which the complexity thesis has explanatory power in this regard.

The approach inevitably has a number of limitations. In particular, data for youth offending, and reoffending, record incidents that are detected and receive a formal criminal justice sanction. They are accordingly susceptible to changes in policy and practice. This limitation is however mitigated in part by an explicit recognition of this potential in the analysis. Perhaps more importantly, published statistics are not always disaggregated in ways that allow analysis which would better illuminate some of the issues discussed. Attention is drawn to such deficiencies in the data at relevant points in the argument.

As noted previously, the issue of whether or not there is other evidence, not captured in the reoffending data, that the needs of children in the youth justice system have become more pronounced is not addressed. The discussion of complexity is accordingly a relatively narrow one that deliberately focuses on its deployment to explain trends in reoffending and, conversely, whether recidivism data in and of themselves suggest that the youth justice cohort as whole has a greater propensity to offend.

\section{$\underline{\text { Recent youth justice reoffending trends }}$}

\footnotetext{
${ }^{3}$ Reoffending data require a follow up period which, in the case of custodial sentences, cannot commence until the point of release. As a consequence, publication of figures for recidivism inevitably lag behind those for children subject to caution or conviction.
} 
The caveats in relation to the utility of recidivism as a measure of performance notwithstanding, there is nonetheless merit in exploring what recent reconviction statistics might reveal about developments in youth justice. As suggested above, closer analysis of the data casts doubts over claims that trends shown therein provide evidential support for an allencompassing trend towards a cohort that is more entrenched in its offending and more difficult to rehabilitate.

Reference has already been made to the fact there was a 5.2 percentage point increase in the rate of children's reoffending between 2008 and 2016. However, as shown in table 1, this tendency has been driven largely by a rise associated with pre-court disposals: the proportion of children proved to have reoffended within twelve months of receiving a caution ${ }^{4}$ rose by 5.4 percentage points, from $25.4 \%$ to $30.8 \%$ between 2008 and 2016 . Over the same period, by contrast, the equivalent figures for first tier penalties ${ }^{5}$ and custodial sentences all declined, by 4.5 and 7.2 percentage points respectively (Youth Justice Board/ Ministry of Justice, 2018: table 9.7).

Table 1

\section{Proven reoffending of children by selected index disposal 2008 and 2016}

\begin{tabular}{|l|c|c|c|}
\hline Disposal & \multicolumn{2}{|c|}{ Proportion of children reoffending } & $\begin{array}{c}\text { Percentage point } \\
\text { change: 2008-16 }\end{array}$ \\
\hline Caution & $\mathbf{2 0 0 8}$ & $\mathbf{2 0 1 6}$ & \\
\hline $\begin{array}{l}\text { First tier } \\
\text { penalty }\end{array}$ & $25.4 \%$ & $30.8 \%$ & 5.4 \\
\hline $\begin{array}{l}\text { Custodial } \\
\text { sentence }\end{array}$ & $47.8 \%$ & $43.3 \%$ & -4.5 \\
\hline
\end{tabular}

The position in relation to community sentences is less straightforward: the youth rehabilitation order (YRO) was introduced by the Criminal Justice and Immigration Act 2008, with effect from November 2009, replacing a range of existing community orders, of

\footnotetext{
${ }^{4}$ The Legal Aid Sentencing and Punishment of Offenders Act 2012 replaced the existing pre-court system of reprimands and final warnings with youth cautions from 8 April 2013. For ease of exposition, the term caution here, and elsewhere in the article, includes those earlier disposals.

${ }^{5}$ First-tier penalties comprise discharges, fines, the reparation order and the referral order.
} 
which the supervision order was by far the most widely used (Nacro, 2010). Directly comparable figures over the full reference timeframe for orders classified as community sentences are not therefore available. However, on the reasonable assumption that the YRO is functionally equivalent to the range of disposals it replaced, there has also been a reduction in reoffending for such sentences of 3.2 percentage points.

These contrasting trends are clearly not compatible with a single explanation drawing on the notion that the youth justice population has become more challenging, which would lead one to anticipate increases in recidivism across the range of disposals. At the same time, it would be perverse, given the discussion to date, to suppose that improvements in the effectiveness of youth justice interventions could account for the falls in reoffending for court orders. This is particularly so given the abundant evidence that conditions for, and treatment of, children in the custodial estate have deteriorated sharply (see for instance, HM Inspector of Prisons, 2018; Bateman, 2016b; Joint Committee on Human Rights, 2019) and stringent criticism of resettlement practice (Her Majesty's Inspectorate of Probation, 2015). More generally, there has been a significant reduction in resources available to youth offending teams which have fallen by more than a quarter in the past five years (Youth Justice Board/ Ministry of Justice, 2019). While statutory caseloads have of course also declined, mitigating to some extent the impact of constrained budgets, capital expenditure on premises and administration tends to be constant so that diminished resources are disproportionately experienced in terms of staffing levels and services to children where the savings can be more readily made. More pertinently perhaps, as the number of children subject to formal disposals lessened, most services have shifted focus to incorporate considerable preventive work as a 'core business', offsetting the potential benefits, in terms of resources, of increased diversion (Youth Justice Board, 2015: 16. See also, Deloitte, 2015). Related to this, there is some evidence that YOT practitioners perceive their workloads to be largely unchanged due to a greater concentration of children with complex needs on their caseloads, a proliferation in associated 'paperwork' and cuts to local welfare services, resulting in pressure on YOTs to bridge the divide (Wigzell, forthcoming).

\section{Making sense of the data: cautions and incarceration}

If the standard narrative, in the form of the complexity thesis, does not fully account for the patterns shown in the statistics, it does not follow that it should be rejected as having no 
explanatory power. In fact there are grounds to suppose that a changing profile of children in receipt of pre-court disposals might indeed have impacted on levels of reoffending for that group.

One might anticipate that the FTE target would have a disproportionate impact on the number of children given a caution since those committing relatively low level offences, and those with no previous record of criminality, would be more likely candidates for informal diversionary measures. The same process, by removing from the pre-court part of the system a cohort of children least likely to reoffend, would thereby be expected to raise the recidivism rate for that group. This assumption is supported by the trend data for different disposal types. As shown in figure 1, the decline in the number of children cautioned, over the relevant period, was considerably more pronounced than that associated with convictions. (The fall in relation to the latter was similar for cases resulting in both custodial and non-custodial outcomes.) The potential for a change in the characteristics of the pre-court cohort - and scope for the complexity thesis to apply to that population - is accordingly greater. In other words, the larger decline in the number of children given cautions, by comparison with other disposals, is likely to have been a consequence of a filtering out of children with lower level of needs, leaving behind a more complex group with a higher likelihood of reoffending which is then reflected, as the complexity thesis predicts, in increased recidivism for this group.

\section{Figure 1}

\section{Percentage fall in different disposal types: 2008-2016}

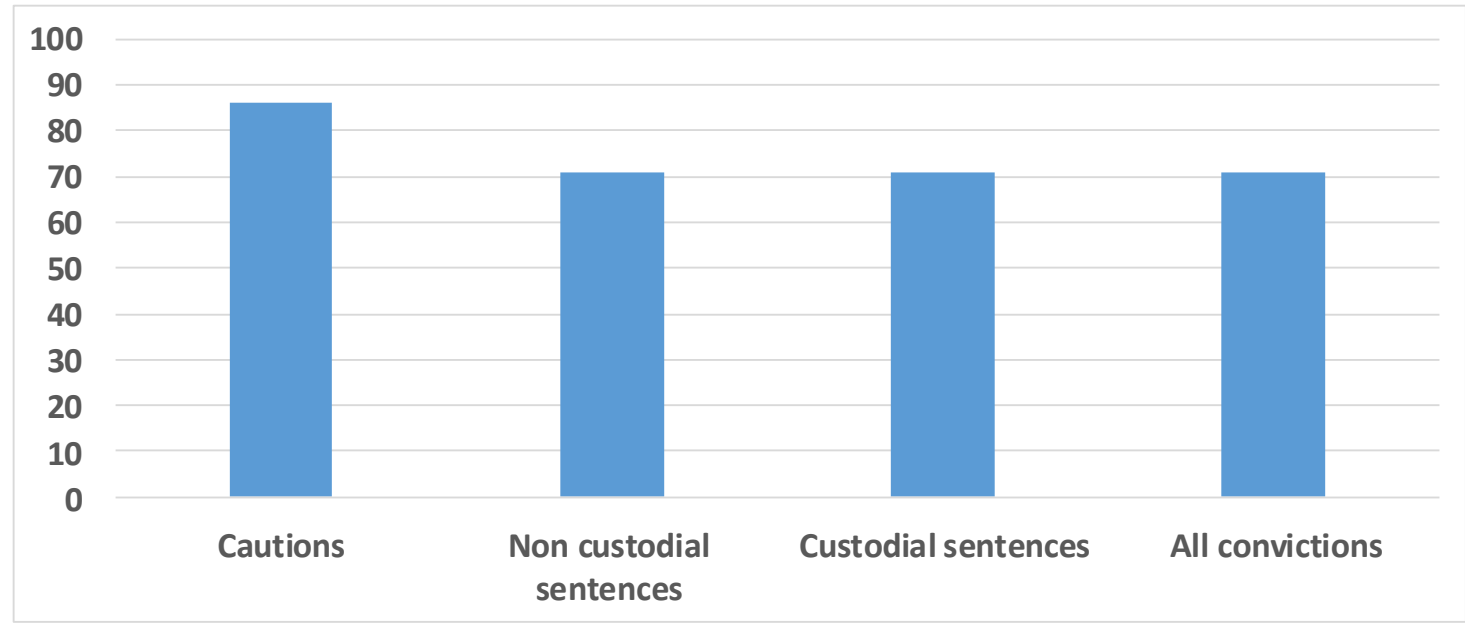


But the decline in the number of convictions - though smaller - has also been substantial. Some account is therefore still required of why corresponding falls in the population of children in receipt of a court order have not also resulted in rising recidivism for that group, albeit that one would expect the trend to be more muted than that displayed by the pre-court court cohort.

The fall in proven reoffending following a custodial disposal might be considered particularly surprising given that it is generally acknowledged, as noted above, that conditions in the children's secure estate have deteriorated markedly in recent years and a range of commentaries that point to a more challenging population in the secure estate (Wood et al, 2017; Green, 2019; HM Inspector of Prisons, 2018; Bateman, 2016b; Hazel and Lockwood, 2016), with an escalation in already excessive levels of violence, self-harm, the use of restraint and isolation from peers. In the light of such evidence, any suggestion that improvements in the effectiveness of custodial provision might have contributed to lower rates of recidivism would appear to lack credibility.

A rather different account has been proposed that proceeds from the well attested tendency for the large majority of children to grow out of crime as they mature (McAra, 2018). Bateman (2017) has pointed out that the fall in the custodial population has occasioned a rise in the average age of children who are detained and increases in the length of incarceration. In combination, these factors entail that release occurs, on average, at a later age - closer to the point at which the natural process of desistance would be expected to commence - than previously.

There is statistical support that lends plausibility to the account. Between 2008 and 2016, the number of children in custody below the age of 15 years fell by almost $80 \%$; the equivalent figure for 16-17-years-olds was considerably lower at around 65\%. Recidivism data are not disaggregated by age and disposal type, but, as shown in table 2, the overall rise in reoffending since 2008 has been substantially faster for the younger age group, who are both underrepresented in custody and overrepresented in the population of children receiving a caution. A similar pattern is evident for the frequency of reconviction: for the youngest age group, the average number of re-offences per child rose from 2.92 to 4.03 between 2008 and 2016, compared to a jump from 3.11 to 3.71 for 15-17-year-olds (Youth Justice Board / Ministry of Justice, 2018). 
Table 2

Proven reoffending of children by age group:

2008 and 2016

\begin{tabular}{|l|c|c|c|}
\hline Age range & \multicolumn{2}{|c|}{ Proportion of children reoffending } & $\begin{array}{c}\text { Percentage point } \\
\text { change: 2008-16 }\end{array}$ \\
\hline & $\mathbf{2 0 0 8}$ & $\mathbf{2 0 1 6}$ & \\
\hline $10-14$ years & $33.5 \%$ & $43.0 \%$ & 9.5 \\
\hline $15-17$ years & $38.9 \%$ & $42.0 \%$ & 3.1 \\
\hline
\end{tabular}

Over the same period, the average duration of custodial episode rose from 76 to 90 days

(Youth Justice Board / Ministry of Justice, 2013; 2018) and recorded reoffending rates decline in line with sentence length, as indicated in table 3.

Table 3

Proven reoffending for custodial sentences by sentence length: 2016

\begin{tabular}{|l|c|}
\hline Length of custodial sentence & $\begin{array}{c}\text { Proportion of children } \\
\text { reoffending }\end{array}$ \\
\hline Less than or equal to 6 months & $73.5 \%$ \\
\hline More than 6 months to less than 12 months & $71.4 \%$ \\
\hline 12 months to less than 4 years & $62.0 \%$ \\
\hline
\end{tabular}

The trend towards a reducing rate of reoffending for children leaving custody is not the pattern that would be predicted by the complexity thesis. There are however good grounds for supposing that the data can be readily explained as a function of the age-crime curve.

\section{Making sense of the data: non-custodial sentencing}


The complexity thesis would lead one to anticipate an increase in reoffending rates for children subject to community-based court orders, but, as we have seen, the statistical evidence appears to show a contrary trend. So far as we aware, there have been no previous attempts to explain this apparent paradox. The analysis offered here is accordingly exploratory and, of necessity, limited by the incomplete nature of the published data. It is however possible to consider three factors that might feature in any satisfactory account.

\section{Age}

The first of these concerns age. If, as argued previously, an increase in the average age of children in the custodial population might help to account for the fall in the reoffending for that group, it might be thought relevant that the age profile of children who receive pre-court disposals is also younger than for those who are convicted. In 2016, for instance, just over a third of children given a caution were below the age of 15 years, compared with $21 \%$ of those in receipt of a court order (Ministry of Justice, 2018). On the other hand, as shown in figure 2 , the representation of younger children in the pre-court cohort has fallen more rapidly than in the latter. The fact that the average age of children in receipt of non-custodial sentences has risen very slightly would not therefore appear to contribute to an understanding of why reoffending trends for this group should have diverged from those for pre-court sanctions.

\section{Figure 2}

Children aged 10-14 who received a caution or conviction as a percentage of all children in those groups: 2008-2016 


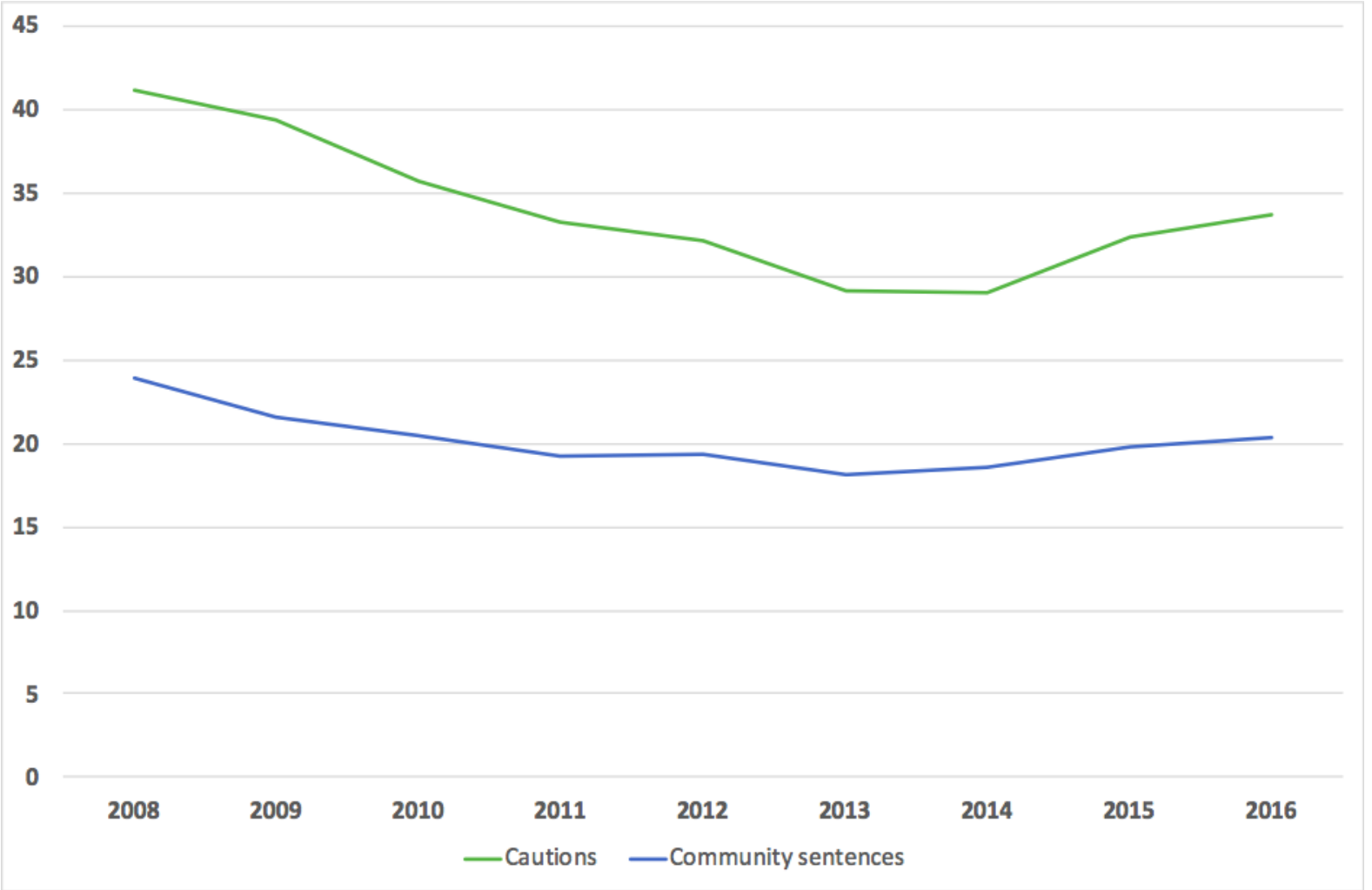

\section{Offence type}

If shifts in age shed little light on the problem, analysis of index offences might offer some suggestive insights. As the number of children in the youth justice system has contracted, the profile of offences occasioning a formal sanction has altered. Moreover, the nature and extent of the shift has differed in important respects for cautions and community sentences. At the same time, reconviction rates naturally vary according to the index offence and these too change over time.

As a consequence, if the shift in the profile of offences leading to community sentences involved relative increases in those crimes with a declining, or stable, rate of conviction, while the profile of cautions showed an opposite trajectory, these changes would provide a partial account of patterns shown in the reconviction data. Moreover, if serious offending had risen more sharply among the pre-court population, and such matters were associated with higher levels of reoffending, then the complexity thesis might after all play a legitimate explanatory role. 
In the event, the evidence in this regard proves to be somewhat mixed.

Table 4 shows index offence type by changes in reconviction rates between 2008 and 2016, grouped according to the direction of change over that period. Offences associated with a decline in recidivism are shown at the top of the table; those manifesting a rise, appear in the lower rows. Data is also provided for each index offence as a proportion of all offences leading to caution or community sentence, indicating the direction and extent of change of that proportion over the same period (data drawn from Ministry of Justice, 2018 and Youth Justice Board / Ministry of Justice, 2018).

Table 4

Index offence type by rate of reconviction and proportion of total offences leading to caution or community sentence, with changes over time (percentage points):

$$
2008-2016^{67}
$$

\begin{tabular}{|l|c|c|c|c|c|c|c|c|c|}
\hline \multicolumn{1}{|c|}{$\begin{array}{c}\text { Index } \\
\text { offence }\end{array}$} & \multicolumn{4}{|c|}{ Reconviction rate } & \multicolumn{3}{c|}{$\begin{array}{c}\text { As a proportion of all } \\
\text { offences leading to } \\
\text { caution }\end{array}$} & \multicolumn{2}{c|}{$\begin{array}{c}\text { As a proportion of all } \\
\text { offences leading to a } \\
\text { community sentence }\end{array}$} \\
\hline & $\mathbf{2 0 0 8}$ & $\mathbf{2 0 1 6}$ & $\begin{array}{c}\text { PP } \\
\text { change }\end{array}$ & $\mathbf{2 0 0 8}$ & $\mathbf{2 0 1 6}$ & $\begin{array}{c}\text { PP } \\
\text { change }\end{array}$ & $\mathbf{2 0 0 8}$ & $\mathbf{2 0 1 6}$ & $\begin{array}{c}\text { PP } \\
\text { change }\end{array}$ \\
\hline $\begin{array}{l}\text { Sexual } \\
\text { offences }\end{array}$ & $18.8 \%$ & $15.2 \%$ & -3.6 & $0.5 \%$ & $1.8 \%$ & 1.3 & $0.7 \%$ & $2.1 \%$ & 1.4 \\
\hline Robbery & $49.3 \%$ & $46.0 \%$ & -3.3 & $0.3 \%$ & $0.4 \%$ & 0.1 & $4.2 \%$ & $4.4 \%$ & 0.3 \\
\hline $\begin{array}{l}\text { Possess } \\
\text { Weapon }\end{array}$ & $37.7 \%$ & $36.3 \%$ & -1.4 & $2.6 \%$ & $7.3 \%$ & 4.7 & $4.0 \%$ & $8.0 \%$ & 4.1 \\
\hline Violence & $31.6 \%$ & $31.0 \%$ & -0.6 & $7.2 \%$ & $7.5 \%$ & 0.4 & $5.9 \%$ & $5.8 \%$ & -0.1 \\
\hline & & & & & & & & & \\
\hline
\end{tabular}

${ }^{6}$ Criminal damage includes offences of arson.

${ }^{7}$ Figures may always sum due to rounding. 


\begin{tabular}{|l|c|c|c|c|c|c|c|c|c|}
\hline $\begin{array}{l}\text { Criminal } \\
\text { Damage }\end{array}$ & $37.9 \%$ & $39.0 \%$ & 1.1 & $3.4 \%$ & $2.3 \%$ & -1.1 & $3.3 \%$ & $1.5 \%$ & -1.8 \\
\hline $\begin{array}{l}\text { Drugs } \\
\text { offences }\end{array}$ & $38.7 \%$ & $40.0 \%$ & 1.4 & $8.6 \%$ & $13.9 \%$ & 5.3 & $5.8 \%$ & $7.6 \%$ & 1.9 \\
\hline Public order & $48.4 \%$ & $51.2 \%$ & 2.7 & $1.1 \%$ & $1.8 \%$ & 0.7 & $1.8 \%$ & $3.3 \%$ & 1.5 \\
\hline Miscellaneous & $46.7 \%$ & $49.7 \%$ & 3.0 & $2.0 \%$ & $2.4 \%$ & 0.4 & $4.6 \%$ & $4.2 \%$ & -0.4 \\
\hline Fraud & $25.7 \%$ & $29.4 \%$ & 3.7 & $0.7 \%$ & $0.6 \%$ & -0.1 & $0.3 \%$ & $0.6 \%$ & 0.3 \\
\hline $\begin{array}{l}\text { Summary - } \\
\text { non motoring }\end{array}$ & $37.7 \%$ & $43.2 \%$ & 5.5 & $40.7 \%$ & $42.0 \%$ & 1.4 & $40.1 \%$ & $41.8 \%$ & 1.6 \\
\hline \begin{tabular}{l} 
Theft \\
\hline
\end{tabular} & $34.5 \%$ & $47.1 \%$ & 12.6 & $32.9 \%$ & $20.0 \%$ & -12.9 & $25.9 \%$ & $17.6 \%$ & -8.3 \\
\hline $\begin{array}{l}\text { Summary } \\
\text { motoring }\end{array}$ & 37.7 & 37.0 & -0.7 & N/A & N/A & & 3.4 & 3.0 & 0.4 \\
\hline
\end{tabular}

It should be acknowledged that there are considerable limitations to the data. The offence categories each capture a broad array of behaviours and take no account of the nature or extent of previous offending. A degree of caution should therefore be exercised in treating them as straightforward indicators of the seriousness of offending. It is also unclear what kinds of incidents are included in summary non-motoring offences; this is particularly problematic given that such matters account for more than $40 \%$ of cautions and community sentences. ${ }^{8}$ Finally the dataset for cautions does not have a distinct category for summary motoring offences. Figures for community sentences in relation to these offences are for this reason presented separately in the table.

These limitations notwithstanding, it is possible to make a number of potentially useful observations. First, as might be anticipated given that overall recidivism has grown over the relevant period, the recorded reconviction rate has risen for most offence types, but not all. In contrast to what might be predicted by the complexity thesis, offences which show reductions in reoffending are, for the most part, those which might be considered among the most serious: including violence, robbery and sexual offending. It is not at all obvious why this might be, but a possible explanation is offered in due course.

At the other end of the scale, by far the biggest rise in reconvictions rates - a percentage point increase of 12.6 - is associated with theft, followed by that for summary non-motoring

\footnotetext{
${ }^{8}$ It seems likely that at least some of the offences included in the summary non-motoring category would fit better in other categories.
} 
offences. Most of the incidents falling within these two categories are unlikely to be matters of the utmost gravity. These two offences types, in combination account for around six in every ten matters leading to caution or community sentence. It would thus appear that the rise in reoffending has been driven largely by changes in reconviction for offending towards the lower end of the scales of seriousness; a pattern which is not obviously consistent with expectations that might be derived from the complexity thesis.

As noted above, the profile of incidents leading to a formal youth justice sanction has changed considerably as the number of children receiving such sanctions has declined. As shown in table 4 , the most dramatic shift has been a reduction in the proportion of sanctions imposed for offences of theft. While this trend is consistent with the suggestion that less serious offences have been progressively filtered out of the system, the fall has been substantially lower for community sentences than for cautions (a percentage point decline of 8.3 for the former as against 12.9 for the latter). Again this pattern is not obviously supportive of the complexity thesis since one might anticipate that lower level offences would increasingly attract a pre-court sanction rather than a conviction if there had been a consistent process of down tariffing. It is, in this context, perhaps telling that in 2016 , almost $60 \%$ of community sentences were imposed for matters of theft or summary non-motor offences.

There have, it is true, been proportionate rises in some of what might be considered more serious offences within the two cohorts, such as sexual offending, robbery and weapons possession. For the first two of these, the relative increase has been greater for community sentences than for cautions. Yet the overall extent of change is small and the differences between the two cohorts is modest. Sexual offences rose as a proportion of all episodes leading to a caution by just 1.3 percentage points compared to 1.4 percentage points for community sentences; the equivalent figures for robbery were 0.1 and 0.3 percentage points respectively. Conversely, the relative increase in sanctions imposed for possession of offensive weapons was larger for cautions than for community sentences; and while there was a small proportionate rise in cautioning for violence against the person, such offences actually fell - albeit very slightly - as a proportion of convictions (by 0.1 ). None of these figures supports the view that the offending of children subject to community supervision is becoming substantially more serious. 
The primary difference between cautions and community sentences, in terms of changes in offence profile, relates to theft. Such offences account for the largest proportionate decline in both cohorts, but the fall is considerably sharper for the group receiving cautions. To the extent that this indicates that the youth justice population is characterised by more serious offending, it would seem that this development has impacted the cautioning cohort to a far greater degree than children receiving a community sentence. The complexity thesis would again appear to require modification and qualification.

As highlighted above, theft also manifests by far the largest change - in the form of a sharp rise - in rates of reconviction. This poses something of a conundrum: the fall in the prevalence of theft offences leading to a community sentence might, taken in isolation, help to account for the decline in reconviction rates for those orders; but the logic of this position would also predict a larger decline in recidivism for cautions given that there has been a more rapid reduction in the proportion of pre-court disposals imposed for theft. As we have seen, the data for cautions shows precisely the opposite pattern. Whatever the explanation for this apparent paradox, it is clear that the complexity thesis does not, on the face of it, offer an adequate account.

\section{Previous offending history}

As noted above, data bated on offence type is limited in certain respects. Moreover, it illuminates just one aspect of changes in youth justice cohort. A further element, of at least equal significance, is the extent of lawbreaking prior to receiving the disposal against which reconviction is measured. Some caveats are again in order since statistics for previous history, just as those for reconviction, are generated from offending leading to a formal sanction rather than offending behaviour itself (Bateman, 2015). This is particularly relevant in the current context since the complexity thesis relies in part on the, reasonable, assumption that a significant proportion of detected offending which in an earlier period would have attracted a formal response has, since 2008, been dealt with informally (Bateman, 2017). As we have seen, however, the anticipated rise in reconvictions, which such an assumption would predict, is not borne out by reoffending data for community sentences. Analysis of available statistics in relation to the antecedent history of children at different stages of the youth justice system helps to throw further light on this puzzle. 
The first point to note is a positive correlation between the extent of previous offending and recidivism; as shown in table 5, children with eleven or more previous offences recorded against them have a reconviction rate more than three times that of children with no antecedent criminal record (Youth Justice Board/ Ministry of Justice, 2018).

\section{Table 5}

\section{Proven reoffending by number of previous offences: 2016}

\begin{tabular}{|l|c|}
\hline Previous offences & Percentage of cohort reoffending \\
\hline None & $24.7 \%$ \\
\hline 1 to 2 previous offences & $42.3 \%$ \\
\hline 3 to 6 previous offences & $56.8 \%$ \\
\hline 7 to 10 previous offences & $64.9 \%$ \\
\hline 11 or more previous offences & $76.0 \%$ \\
\hline
\end{tabular}

It is possible to discern in the data some support for the complexity thesis up to a certain point: between 2008 and 2016, there has been a rise in the rate of reoffending for children with no previous offending from $20.8 \%$ to $24.7 \%$. There has been a comparable growth in the rate of reconviction for children with one or two previous offences from $38.7 \%$ to $42.3 \%$. For children with higher levels of previous convictions, recidivism rates have, conversely, fallen. Such a pattern might be thought consistent with an assumption that those with a limited record of offending have benefited from the FTE target, and have, as a consequence, tended to enter the formal system at a later stage of delinquency than their peers who, in an earlier period, had already acquired a record of previous formal sanctions.

The impact of the target on the youth justice population as a whole can be viewed through different lenses. On the one hand the absolute number of FTEs in the system has fallen sharply, by almost $82 \%$ between 2008 and 2016. But considered in relation to the overall decline in youth justice throughput, the reduction appears to be more modest; sanctions against FTEs as a proportion of all disposals imposed has reduced from $46 \%$ to $43 \%$. The fall in non-FTEs has in other words been more pronounced.

Significantly, this latter reduction is, moreover, not evident across all types of youth justice outcome. Some disposals have been characterised by a rise in the proportion of sanctions imposed on FTEs. This is not surprising, in itself, since potential FTEs cannot be diverted 
from the system indefinitely and, if they continue to come to police attention, will be at increasing risk of formal processing. One might anticipate that this would be particularly reflected in cautioning since this is the first option available for such children. However figures show that, between 2008 and 2016, the proportion of FTEs among the pre-court disposal cohort has fallen slightly. Perhaps more unexpected is that there has been a substantial increase in the proportion of FTEs receiving community sentences, albeit from a lower baseline.

As shown in figure 3, while the proportion of cautions imposed on FTEs declined by two percentage points, there was an increase for community sentences of sixteen percentage points, almost tripling FTE representation in the community sentence cohort from $9 \%$ to $25 \%$. Given that FTEs have a much lower likelihood of reoffending than other children, these shifts go some way to account for different trends in reconviction rates for these two disposal types.

It would appear that one of the (unintended) consequences of the FTE target is that a larger proportion of children with no criminal record are 'skipping' the caution stage and being propelled straight to more intensive forms of sentencing. Contrary to the complexity thesis, the community sentence cohort appears to have become less entrenched in offending than in the period prior to 2008. Surprisingly, perhaps, the principal reason that rates of reoffending have declined for children subject to a community sentence while those for children subject to cautions has risen, is that the former group embodies a lower risk of reoffending because it includes a considerably higher proportion of FTEs than hitherto. While such evidence does not, in itself, undermine the complexity theory it does raise questions as to whether, and to what extent, children subject to formal intervention are, in fact, 'much more embedded ... in a culture of offending' (Alun Michael, cited in House of Commons Justice Committee, 2014: 94).

\section{Figure 3}

First time entrants as a proportion of children receiving cautions and community sentences: 2008 and 2016 


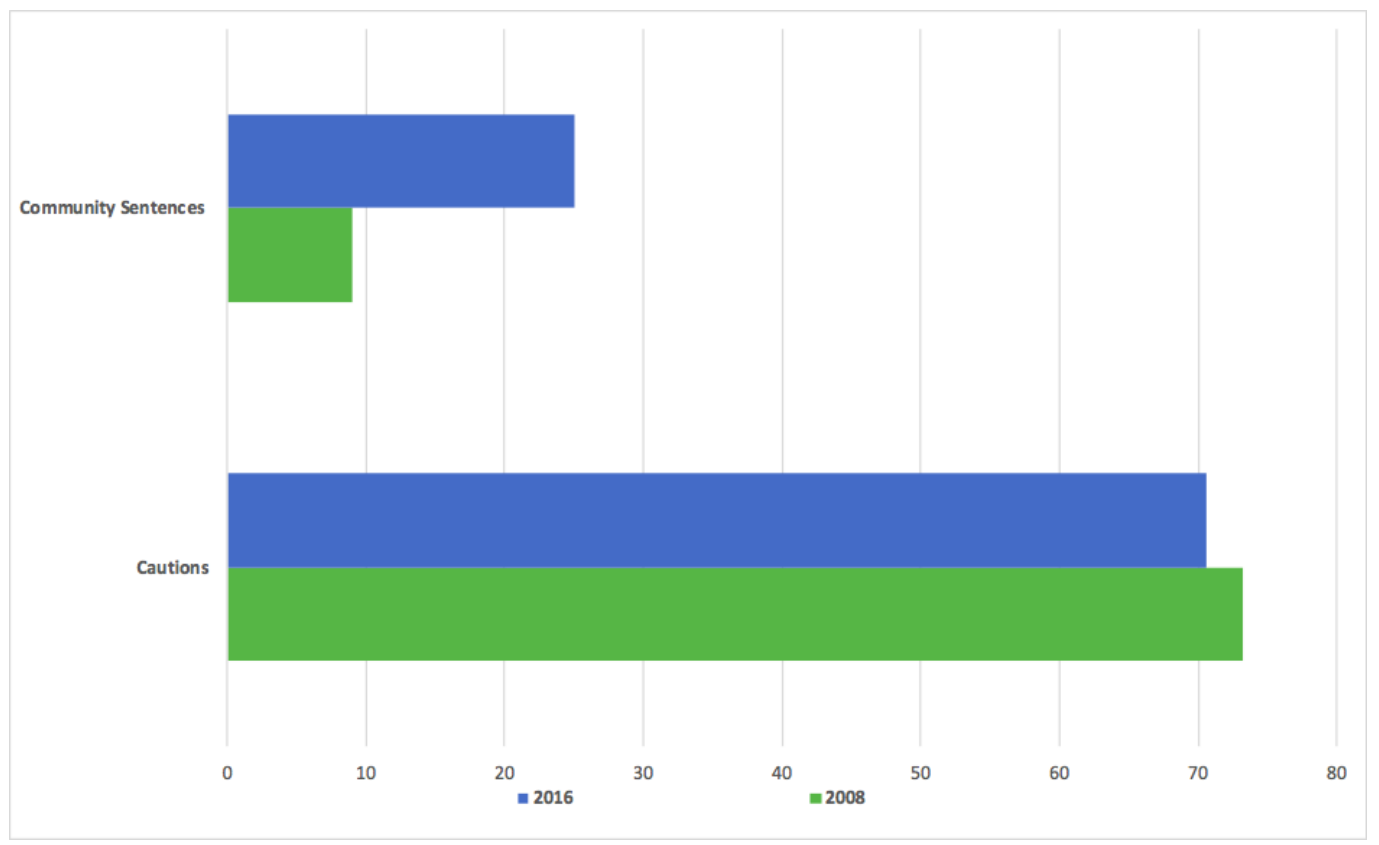

At this point, it is worth revisiting an issue raised earlier pertaining to a decline in reconviction rates for some of the more serious offence types. One possibility is that certain types of high profile behaviours - such as sexual offending and weapons possession - have, to some extent, bypassed the diversionary impulse that has led to other, lower level, offences being kept away from the formal justice system unless the child offended repeatedly. In that event, a considerable proportion of children engaging in more serious forms of behaviour might be fast-tracked into the court system, by-passing pre-court options, and attract a community sentence even though they have no previous offences recorded against them. This group of children would have a corresponding lower risk of recidivism. Unfortunately the data cannot be disaggregated in a manner that would allow analysis to confirm the hypothesis, but it is a consideration that may warrant further research.

\section{$\underline{\text { Conclusion }}$}

This article has sought to question the value of reconviction as an unproblematic measure of the performance of the youth justice system. It has also attempted to challenge a standard narrative that has emerged to explain recent rises in children's recidivism which understands such rises as an expected outcome of increased complexity. The assumption that increased revidivism is a function of the youth justice cohort having become more challenging and entrenched in its behaviour as a consequence of rising diversion, may capture a partial truth. 
In particular, there is reason to support that it might offer a useful explanatory framework for understanding at least some of the rise in reoffending associated with cautioning. However, it cannot account for the simultaneous decline in the level of reoffending manifested in other parts of the system.

In particular, the thesis is mistaken in implying that children subject to a community sentence tend to commit more serious offences and are more entrenched in their offending than hitherto. Indeed, the falling reoffending rates for that group over the last eight years appear to best understood as a manifestation of a substantial rise in the proportion of this cohort who are FTEs. Contrary to claims that the current youth justice cohort is likely to be more 'criminogenic' and harder to rehabilitate, the evidence adduced here appears to show that a substantial, and increasing, proportion of children subject to court orders have, in fact, a very limited offending history and as a consequence tend to show lower rates of reoffending.

The analysis presented is restricted by limitations of the published data which do not allow disaggregation by reconviction rate, age, offence type and criminal history. Such data would be required to test fully some of the explanations offered here. It is nonetheless clear from the available evidence that policy makers might do well to abandon the existing pre-occupation with reconviction as a measure of 'effectiveness' since the variables that combine to deliver that single figure are too complicated to provide a meaningful indicator of success.

In many ways, this is unsurprising for reasons that go beyond statistical anomaly. Focusing on such a target overlooks the fact that, for many children subject to youth justice intervention, simply engaging in the supervision process is an achievement, the outcome of which may only be discernible years later as they move towards desistance. Reconviction data, while undoubtedly useful for some purposes, neglect the element of practice that practitioners and children often regard as most meaningful. As Souhami (2007: 66) notes in her ethnographic study of a youth offending team, workers felt that 'meaningful [quantitative] measurement of their work was impossible' because the latter was primarily concerned with the nurturing of interpersonal relationships. As suggested earlier in this paper, such an assessment may be overly pessimistic: it is possible to develop alternative, more eloquent, ways of weighing the impact of youth justice practice that better capture what really matters to children, practitioners and wider society. But insofar as Souhami's critique is directed at reoffending it is well made. The arguments presented here provide additional 
grounds for thinking that further refinement of outcome measures is warranted. Canton's (2012) call for supervision that is premised on the principle of obliquity provides a powerful rationale for such an undertaking.

\section{References:}

Audit Commission (1996) Misspent Youth: Young People and Crime, Bournemouth: Bourne Press.

Bateman, T. (2006) 'Youth crime and justice: statistical 'evidence', recent trends and responses, in B. Goldson and J. Muncie (Eds) Youth Crime and Justice, London: Sage, 65-77.

Bateman, T. (2010) 'Reoffending as a measure of effectiveness of youth justice intervention: a critical note', Safer Communities, 9 (3), 28-35.

Bateman, T (2014) 'Reducing recidivism: a misguided target?' in AYM news, November 2014: 13-15.

Bateman, T (2015) 'Trends in detected youth crime and contemporary state responses' in Goldson, B and Muncie, J (eds) Youth crime and justice. 2nd edition. London: Sage, 67-82.

Bateman, T. (2016a) 'Youth Justice News', Youth Justice, 16 (1): 82-91.

Bateman, T (2016b) The state of youth custody. London: NAYJ.

Bateman, T. (2017) The State of Youth Justice 2017: An overview of trends and developments. London: NAYJ.

Bateman, T and Hazel, N (2014) Resettlement of young people leaving custody: lessons from the literature - update March 2014. London: Beyond Youth Custody.

Burnett, R. (2004) 'To reoffend or not to reoffend? The ambivalence of convicted property offenders', in: S. Maruna and R. Immarigeon (Eds.), After Crime and Punishment: Pathways to Offender Reintegration, Cullompton: Willan, 152-180.

Canton, R. (2012) 'The point of probation: on effectiveness, human rights and the virtues of obliquity', Criminology and Criminal Justice, 13(5): 577-593.

Carlile, A. (2014) Independent Parliamentarians' Inquiry into the Operation and Effectiveness of the Youth Court [available at: http://michaelsiefffoundation.org.uk/content/inquiry_into_the_operation_and_effectiveness_of the youth_cour t-uk-carlile-inquiry.pdf

Case, S (2018) Youth justice: a critical introduction. London: Sage.

Criminal Justice Alliance (2011) Response to 'Breaking the Cycle: Effective Punishment, Rehabilitation and Sentencing of Offenders'. London: Criminal Justice Alliance. 
Deloitte (2015) Youth Offending Team Stocktake. London: Deloitte.

Department for Children, Schools and Families (2010) Youth Crime Action Plan Update. London: DCSF.

Farrow, K. Kelly, G. and Wilkinson, B. (2007) Offenders in focus: risk, responsivity and diversity. Bristol: Policy Press.

Garland, D. (2002) The culture of control: crime and social order in contemporary society. Oxford: Oxford University press.

Goldson, B. (ed.) (2000) The New Youth Justice. Lyme Regis: Russell House Publishing.

Gove, M. (2015) Announcement of a review into youth justice, Written statement to Parliament, $11^{\text {th }}$ September 2015 [available at:

https://www.gov.uk/government/speeches/youth-justice (accessed 17th September 2018).

Green, L (2019) Children in custody 2017-18. London: Her Majesty's Inspectorate of Prisons.

Gray, P. (2013) 'Assemblages of penal governance, social justice and youth justice partnerships', Theoretical Criminology, 17 (4) 517-534.

Haines, K and Drakeford, M (1998) Young people and youth justice. Basingstoke: Macmillan.

Haines, K and Case, S (2015) Positive youth justice: children first, offenders second. Bristol Policy Press.

Hazel, N and Lockwood, K (20016) Young people leaving custody: lessons from the literature - update 2016. London: Beyond Youth Custody.

Her Majesty's Inspectorate of Probation (2016) Joint thematic inspection of resettlement services to children by Youth Offending Teams and partner agencies. London: HM Inspectorate of Probation.

Her Majesty's Inspectorate of Probation (2016) Desistance and young people. London: HM Inspectorate of Probation.

Her Majesty's Inspectorate of Probation (2017) HM Inspectorate for England and Wales Annual Report 2017, London: HM Inspectorate of Probation.

Her Majesty's Inspector of Prisons for England and Wales (2018) Annual Report 2017-18. London: The Stationery Office.

Home Office (2004) Juvenile reconviction: results from the 2001 and 2002 cohorts. Online Report 60/04. London: Home Office.

Home Office (2008) Youth crime action plan. London: Home Office. 
House of Commons Justice Committee (2014) Crime reduction policies: a co-ordinated approach? First Report of Session 2014-15. London: House of Commons

Joint Committee on Human Rights (2019) Youth detention: solitary confinement and restraint. London: Joint Committee on Human Rights.

Johns, D. Williams, K. and Haines, K. (2017) 'Ecological Youth Justice: Understanding the Social Ecology of Young People's Prolific Offending', Youth justice 17 (1): 3-21.

Kemshall, H (2008) 'Risks, rights and justice: understanding and responding to youth risk' in Youth Justice 8(1): 21-37.

Matza, D. (1964) Delinquency and Drift, New Jersey: Transaction Publishers.

McAra, L (2018) 'Child-friendly youth justice?' in Bateman, T, Goodfellow, P, Little, R and Wigzell, A (eds) Child-friendly youth justice. London: NAYJ: 5-14.

McNeill, F. (2006) 'A desistance paradigm for offender management', Criminology and Criminal Justice, 6 (1), 39-62.

McVie (2005) 'Patterns of deviance underlying the age-crime curve: the long term evidence', British Society of Criminology e-journal 7, 1-15.

Ministry of Justice (2008) Re-offending of juveniles: new measures of re-offending 2000-2005. England and Wales. Statistics bulletin 9 May 2008. London: Ministry of Justice.

Ministry of Justice (2010) Re-offending of juveniles: results from the 2008 cohort. Statistics bulletin. London: Ministry of Justice.

Ministry of Justice (2017) How the measure of proven reoffending has changed and the effect of these changes. London: Ministry of Justice.

Ministry of Justice (2018) Criminal Justice System statistics quarterly: December 2017. London: Ministry of Justice.

Nacro (2010) The youth rehabilitation order. Youth crime briefing. London: Nacro.

National Association for Youth Justice (2018) Manifesto 2018/2019. London: NAYJ.

Rutherford, A (1992) Growing out of crime. 2nd edition. Winchester: Waterside press

Souhami, A (2007) Transforming Youth Justice: Occupational identity and cultural change, London: Routledge.

Wigzell, A. (forthcoming) Ethnographic perspectives on youth justice supervision and the supervisory relationship in England, $\mathrm{PhD}$ thesis, University of Cambridge.

Wood, A, Bailey, S and Butler, R (2017) Findings and recommendations of the Youth Custody Improvement Board. London: Ministry of Justice. 
Youth Justice Board / Ministry of Justice (2013) Youth Justice statistics 2011 - 2012: supplementary volumes. London: Ministry of Justice.

Youth Justice Board/ Ministry of Justice (2015) Youth Justice statistics 2013 - 2014:

supplementary volumes [available at: https://www.gov.uk/government/statistics/youth-justiceannual-statistics-2013-to-2014 (accessed 22 ${ }^{\text {nd }}$ August 2018)].

Youth Justice Board (2017) The Youth Justice Board for England and Wales: Annual Report and Accounts 2016-17. London: Youth Justice Board

Youth Justice Board/ Ministry of Justice (2018) Youth Justice Statistics 2016/17, England and Wales. London: MoJ

Youth Justice Board/ Ministry of Justice (2019) Youth Justice Statistics 2017/18, England and Wales. London: MoJ

Youth Justice Board (2015) Youth offending teams: making the difference for children and young people, victims and communities. London: Youth Justice Board

Youth Justice Board (2019) Youth Justice Board for England and Wales: Business plan 2019-2020. London: Youth Justice Board 